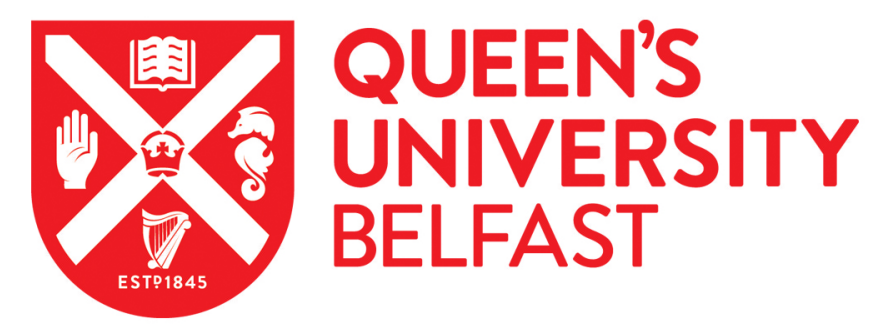

\title{
Immunosensor array platforms based on self-assembled dithiols for the electrochemical detection of tetrodotoxins in puffer fish
}

Reverté, L., Campbell, K., Rambla-Alegre, M., Elliott, C. T., Diogène, J., \& Campàs, M. (2017). Immunosensor array platforms based on self-assembled dithiols for the electrochemical detection of tetrodotoxins in puffer fish. Analytica Chimica Acta, 99, 95-103. https://doi.org/10.1016/j.aca.2017.07.052

Published in:

Analytica Chimica Acta

Document Version:

Peer reviewed version

Queen's University Belfast - Research Portal:

Link to publication record in Queen's University Belfast Research Portal

\section{Publisher rights}

Copyright 2017 Elsevier.

This manuscript is distributed under a Creative Commons Attribution-NonCommercial-NoDerivs License

(https://creativecommons.org/licenses/by-nc-nd/4.0/), which permits distribution and reproduction for non-commercial purposes, provided the author and source are cited.

\section{General rights}

Copyright for the publications made accessible via the Queen's University Belfast Research Portal is retained by the author(s) and / or other copyright owners and it is a condition of accessing these publications that users recognise and abide by the legal requirements associated with these rights.

Take down policy

The Research Portal is Queen's institutional repository that provides access to Queen's research output. Every effort has been made to ensure that content in the Research Portal does not infringe any person's rights, or applicable UK laws. If you discover content in the Research Portal that you believe breaches copyright or violates any law, please contact openaccess@qub.ac.uk. 


\title{
Immunosensor array platforms based on self-assembled dithiols for the electrochemical detection of tetrodotoxins in puffer fish
}

Laia Reverté ${ }^{a}$, Katrina Campbell ${ }^{b}$, Maria Rambla-Alegre ${ }^{a}$, Christopher T. Elliott ${ }^{b}$, Jorge Diogène ${ }^{a}$, and Mònica Campàs $^{a *}$

a IRTA, Ctra. Poble Nou, km 5.5, Sant Carles de la Ràpita, Spain.

b Institute for Global Food Security, School of Biological Sciences, Queen's University, David Keir Building, Stranmillis Road, Belfast, UK BT9 5AG.

${ }^{*}$ Corresponding author:

Mònica Campàs

IRTA

Ctra. Poble Nou, km 5.5

43540 Sant Carles de la Ràpita (Tarragona), Spain

e-mail: monica.campas@irta.cat

\begin{abstract}
The recent detection of tetrodotoxins (TTXs) in European fish and shellfish has emphasized the urgent need to develop specific, selective, rapid and easy-to-use methods for their detection to assess the potential risk posed to human health. For this purpose, a dithiol self-assembled monolayer (SAM)-based immunoassay previously performed on maleimide plates (mELISA) has been adapted to gold electrode arrays for the development of an electrochemical immunosensor for TTX. The electrochemical SAM-based immunosensor designed herein, provided an oriented, stable and spaced sensing platform for the determination of TTX, attaining a limit of detection of $2.6 \mathrm{ng} \mathrm{mL}^{-1}$. The applicability of the biosensor array was demonstrated by the accurate quantifications obtained in the analysis of different tissues of several puffer fish species (Lagocephalus lagocephalus, L. sceleratus and Sphoeroides pachygaster) caught along the Mediterranean coast of Spain. The good agreements found between the TTX concentrations determined by the
\end{abstract}


immunosensor array platforms and those determined by mELISA, surface Plasmon resonance (SPR) immunosensor and liquid chromatography-high resolution mass spectrometry (LC-HRMS) analysis, proved the feasibility of the approach. The electrochemical immunosensor enables the determination of TTXs at levels as low as $0.07 \mathrm{mg}$ TTX equiv. $\mathrm{kg}^{-1}$ tissue, thus, well below the Japanese value of $2 \mathrm{mg}$ TTX equiv. $\mathrm{kg}^{-1}$ tissue used as a criterion to consider puffer fish safe for consumption. Compared to the colorimetric SAMbased approach, the immunosensor array described herein shows promise towards the development of disposable, portable and compact analysis tools applicable in monitoring programs for the surveillance of fishery products.

Keywords: electrochemical immunosensor array, self-assembled monolayer, dithiol, tetrodotoxin, puffer fish, food safety

\section{Introduction}

Tetrodotoxin (TTX) is a low-molecular-weight potent marine neurotoxin believed to be primarily produced by certain marine endosymbiotic bacteria [1]. Once exogenously produced, it may accumulate through the food webs and enter into other organisms [2], eventually reaching humans. Whilst this toxin was originally discovered in the organs of fish from the Tetraodontidae family, especially puffer fish [3], its distribution has expanded to a wide range of marine organisms including amphibians, echinoderms, cephalopods and bivalve mollusks [4]. Structurally, TTX and several TTX analogues have been described as heterocyclic, heat-stable and hydrophilic compounds [5, 6]. They are well-known selective sodium channel blockers [7], which obstruct neural and muscular transmission with a similar mechanism of action to saxitoxin (STX), a potent Paralytic Shellfish Poisoning (PSP) toxin.

Tetrodotoxin is responsible for numerous human intoxications worldwide in most cases with poisoning occurring following the ingestion of contaminated seafood. Typical poisoning symptoms include mild gastrointestinal effects, respiratory paralysis, numbness and even death [8]. Food poisoning incidents were first restricted to warm water regions, particularly in the Pacific and Indian Oceans, affecting mainly Japan and China [9], where puffer fish (fugu) is legally consumed. Although fatalities and intoxications do still occur in Japan, this risk was reduced by the value of $2 \mathrm{mg}$ TTX equiv. $\mathrm{kg}^{-1}$ of edible portion used as a criterion to consider puffer fish safe for consumption [10]. Although there is no regulatory limit for TTX in Europe, EU regulation establishes that fishery products derived from poisonous fish of the families Tetraodontidae, Molidae, Diodontidae and Canthigasteridae must not be placed in the market [11, 12]. However, given that 
fugu is sometimes offered in some private events, the risk may not be completely discarded [13]. TTX poisoning episodes have also been reported following the consumption of mislabeled fish products [14] and, additionally, may be consumed by accident due to their similarity to other non-poisonous fish.

Recently, puffer fish from the species Lagocephalus sceleratus have been found migrating from the Red Sea to the Mediterranean Sea through the Suez Channel (Lessepsian migration) [15]. Additionally, several reports confirm the increasing occurrence of TTX in European seafood. A first toxic episode was described in 2007 in Málaga (Spain), caused by the consumption of trumpet shells caught in Portugal [16]. Afterwards, two episodes were reported along the Mediterranean coast, following the ingestion of L. sceleratus [17, 18]. In the last two years (2014-2015), TTXs have been found in bivalve mollusk shellfish grown in the south of England [19], along the Greek coast [20] and in the Netherlands [21].

Currently, there is no official method of analysis for TTXs in Europe. Nevertheless, different methodologies have been developed for their detection, being LC-MS/MS analysis [22] and the mouse bioassay (MBA) [23] the most widely employed. Although proven useful techniques, the need of skilled personnel, expensive equipment, standards of TTXs and the establishment of toxicity equivalency factors (TEFs) for LC-MS/MS have hampered their appropriate performance. Additionally, the lack of specificity of MBA in discriminating between other coexisting PSP toxins and the non-availability of certain TTX standards, have restricted its use. Due to these limiting factors and given the increasing occurrence of TTX in Europe, the development of specific, rapid and cost-effective methods as support tools in monitoring programs to ensure human safety is highly required. To date, alternative methods based on antibodies that have been developed for TTX include several colorimetric immunoassays [24-30], two electrochemical immunosensors [31, 32] and optical surface Plasmon resonance (SPR) immunosensors [33-36]. Biosensors for other marine toxins have also been reported in the recent years, showing the increasing interest in the field [37-40].

Recently, a special configuration of a colorimetric immunoassay was used by our group for the development of an ELISA for TTX [27]. This assay was based on the immobilization of TTX through dithiols selfassembled on maleimide plates (mELISA) and provided an ordered and oriented antigen immobilization, which proved to be an efficient, reliable and powerful tool for the precise quantification of TTXs. With the aim of moving towards miniaturized and compact devices, this self-assembled monolayer (SAM)-based strategy for the development of an electrochemical immunosensor for TTX detection was exploited herein. The conversion of the colorimetric immunoassay to the electrochemical immunosensor was achieved by transferring the SAM-based strategy from microtiter plates to arrays of gold electrodes, and by recording the electrochemical signal after selecting the appropriate redox mediator for the horseradish peroxidase (HRP) 
label (Figure 1). Compared to the previous reports of electrochemical immunosensors [31, 32], the dithiolbased SAM strategy provides not only an oriented and stable antigen-modified sensing platform, but also decreases the non-specific adsorption. Additionally, whereas the previous reports were proofs of concept, the present work goes a step further, as demonstrated by the application of the immunosensor array platform to the analysis of natural puffer fish samples. Different tissues of several puffer fish species (L. lagocephalus, L. sceleratus and Sphoeroides pachygaster) were analysed for the accurate determination of TTX equivalent contents and the results were compared to those provided by the previously developed mELISA, by the SPR immunosensor and by liquid chromatography-high resolution mass spectrometry (LC-HRMS) analysis [41].

\section{Materials and methods}

\subsection{Reagents and materials}

The TTX standard was obtained from Tocris Bioscience (Bristol, UK). TTX standard solution was prepared at $1 \mathrm{mg} \mathrm{mL}^{-1}$ in $10 \mathrm{mM}$ acetic acid. The anti-TTX monoclonal antibody (mAb) TX-7F was produced as previously described $[25,36]$. DithiolalkanearomaticPEG6-COOH (carboxylate-dithiol) was purchased from Sensopath Technologies (Bozeman, USA). Anti-mouse IgG (whole molecule)-horseradish peroxidase antibody produced in rabbit (IgG-HRP), bovine serum albumin (BSA), ethanolamine, ethylendiamine, 1-ethyl3-(3-dimethylaminopropyl) carbodiimide hydrochloride (EDC), ethylenediaminetetraacetic acid (EDTA), formaldehyde solution (37\%), 2-(N-morpholino) ethanesulfonic acid hydrate (MES), $N$-hydroxysuccinimide (NHS), potassium chloride, potassium hexacyanoferrate II, potassium hexacyanoferrate III, potassium phosphate dibasic, potassium phosphate monobasic, thioctic acid, TMB liquid substrate, TMB enhanced one component HRP membrane substrate and Tween-20 were all supplied by Sigma-Aldrich (Tres Cantos, Spain). HBS-EP buffer (0.01 M HEPES, $0.15 \mathrm{M} \mathrm{NaCl}, 3 \mathrm{mM}$ EDTA, and 0.005\% Surfactant P20, pH 7.4) was provided by GE Healthcare (Little Chalfont, UK). Maleimide-activated plates were obtained from Thermo Fisher Scientific (Madrid, Spain).

\subsection{Equipment, electrodes and software}

Cyclic voltammetry (CV) measurements were performed with a PGSTAT128N potentiostat purchased from AUTOLAB (Massó Analitica S.A., Barcelona, Spain). Data was collected and evaluated by General Purpose Electrochemical System (GPES) software version 4.9. Disposable screen-printed gold electrodes (SPGE), with gold as working and counter electrodes and silver as a reference electrode (220AT), were purchased from Dropsens S.L. (Oviedo, Spain). 
Chronoamperometries (CA) were recorded with a Palmsens multiplexer potentiostat (Palmsens BV, The Netherlands) and a DRP-CAC8x connector from Dropsens S.L. (Oviedo, Spain). Data were collected and evaluated by PSTrace version 4.7.2 software. The $8 \mathrm{x}$ screen-printed gold electrode arrays, with gold as working and counter electrodes and silver as reference electrode (8X220AT), were purchased from Dropsens S.L. (Oviedo, Spain).

Colorimetric measurements for mELISA experiments were performed with a Microplate Reader, GEN5 2.09 software from BIO-TEK Instruments, Inc. (Vermont, USA).

An SPR device (Biacore Q) with Control Software (Version 3.0.1), BIAevaluation software version 4.1, and CM5 sensor chips were obtained from GE Healthcare Bio-Sciences (Uppsala, Sweden).

LC-HRMS analysis was carried out with an Orbitrap-Exactive HCD (Thermo Fisher Scientific, Bremen, Germany) and data was processed with Xcalibur 3.1 software (ThermoFisher Scientific, Bremen, Germany). The adjustment of calibration curves to sigmoidal logistic 4-parameter equations was performed using SigmaPlot 12.0 (Systat Software Inc., California, USA).

\subsection{Puffer fish samples and toxin extraction}

A total of 6 female puffer fish from NW Mediterranean Sea were used in this study, 3 of them belonging to the species $L$. lagocephalus (1 from Blanes, 1 from Altafulla and 1 from Denia, Spain), 1 to the species $L$. sceleratus (from Denia, Spain) and 2 to the species S. pachygaster (1 from LLançà and 1 from Denia, Spain). One of the L. lagocephalus (determined as non-containing TTX by LC-MS/MS; "blank puffer fish sample") was used for the evaluation of matrix effects and spiking experiments.

Toxin extraction from puffer fish tissues (muscle, skin, liver and gonads) was performed as described previously [27]. Briefly, a double extraction was performed with $0.1 \%$ acetic acid for each tissue. In the case of liver, an additional liquid-liquid partition with hexane was required. The analysis by the mELISA, SPR immunosensor and electrochemical immunosensor was performed with the aqueous extracts, but for the LCHRMS analyses, extracts were evaporated, re-dissolved in methanol and filtered through 0.2- $\mu \mathrm{m}$ nylon filters.

\subsection{Electrochemical immunosensor array platforms}

The titration assay protocol used for the immobilization of TTX through carboxylate-dithiol self-assembled on SPGEs was similar to that used for the mELISA previously described [27], with some modifications of volumes and immobilization supports. The steps taken were as follows: (1) $15 \mu \mathrm{L}$ of 0.1 and $1 \mathrm{mM}$ 
carboxylate-dithiol in $0.1 \mathrm{M}$ potassium phosphate, $10 \mathrm{mM}$ EDTA, pH 7.2 (PBS) were placed on the SPGEs of the array (8x220AT) and self-assembled for 3 h. (2) Carboxylic groups of dithiols were activated by the addition of $15 \mu \mathrm{L}$ of $0.1 \mathrm{M} \mathrm{NHS}$ and $0.4 \mathrm{M} \mathrm{EDC} \mathrm{(1/1,v/v)} \mathrm{in} 25 \mathrm{mM}$ MES, pH 5.5 for $30 \mathrm{~min}$. (3) Activated carboxylic groups reacted with primary amines of ethylenediamine (15 $\mu \mathrm{L}$ of $0.1 \mathrm{M}$ ethylenediamine in PBS) for $30 \mathrm{~min}$, forming amide bonds (4) The remaining carboxylic groups were deactivated by adding $15 \mu \mathrm{L}$ of 1 M ethanolamine in PBS for 30 min. (5) TTX was then immobilized on ethylenediamine through formaldehyde cross-linking following an amino-amino reaction, adding $14.5 \mu \mathrm{L}$ of 0.2 and $2 \mu \mathrm{g} \mathrm{mL}^{-1}$ of TTX in PBS and 0.5 $\mu \mathrm{L}$ of formaldehyde (37\%) for $15 \mathrm{~h}$. Following TTX immobilization, (6) $15 \mu \mathrm{L}$ of 1/800, 1/1,600 and 1/3,200 mAb dilutions in 1\% BSA-PBS were incubated for 30 min. (7) Remaining sites were blocked with 1\% BSAPBS for $30 \mathrm{~min}$. (8) $15 \mu \mathrm{L}$ of IgG-HRP at 1/1,000 dilution were incubated onto the electrodes for $30 \mathrm{~min}$. (9) Finally, TMB enhanced liquid substrate was allowed to react for $10 \mathrm{~min}$ and chronoamperometries (CA) were recorded at $-0.11 \mathrm{~V}$ for $5 \mathrm{~s}$ (current intensities were taken at $0.5 \mathrm{~s}$ ). After each step, electrodes were rinsed with washing buffer $(0.1 \mathrm{M}$ potassium phosphate, $0.15 \mathrm{M} \mathrm{NaCl}, 0.05 \%$ Tween-20, $\mathrm{pH} 7.2)$ and air-dried.

Once the optimum concentrations of carboxylate-dithiol and TTX were selected, three competition assays were performed, the protocol differing from the checkerboard only in step (6). Thus, $7.5 \mu \mathrm{L}$ of 1:800, 1/1,600 and 1/3,200 mAb dilutions were mixed with $7.5 \mu \mathrm{L}$ of TTX standard solution or "sample" (blank puffer fish tissue extract, TTX-spiked puffer fish tissue extract or naturally-contaminated puffer fish tissue extract) and pre-incubated in tubes for $15 \mathrm{~min}$ before placing the mixture on the electrodes for $30 \mathrm{~min}$. Several competitive electrochemical assays were performed differing in the sample used in the competition step: 1) A TTX standard calibration curve was constructed from 0.625 to $80 \mathrm{ng} \mathrm{mL}^{-1}$ in PBS. The background was corrected with respect to the controls without mAb and the curve was fitted to a sigmoidal logistic 4parameter equation. From the equation, inhibitory concentrations (ICs) were calculated. Specifically, the midpoint $\left(\mathrm{IC}_{50}\right)$, the limit of detection (LOD) established as the $\mathrm{IC}_{20}$, and the working range, considering the linear interval of the curve $\left(\mathrm{IC}_{20}-\mathrm{IC}_{60}\right)$, were determined. 2) Puffer fish matrix effects were evaluated using different tissues of a blank puffer fish sample (muscle, skin, liver, and gonads) with no presence of TTXs as determined by LC-MS/MS analysis, using a matrix concentration of $40 \mathrm{mg} \mathrm{mL}^{-1}$. 3) Different puffer fish tissue extracts at a matrix concentration of $40 \mathrm{mg} \mathrm{mL}^{-1}$ were spiked with TTX at 2.5, 5 and $10 \mathrm{ng} \mathrm{mL}^{-1}$ to determine the percentage of toxin observed in spiked-puffer fish tissue extracts with respect to the spiked TTX levels. 4) Finally, extracts of different tissues from 5 puffer fish individuals were analyzed. Toxin standard solution and samples were prepared in PBS, diluted by half and assayed in quadruplicate. 


\subsection{SAM characterization by reductive desorption}

The electrochemical reduction of the thiol-gold bond between the carboxylate-dithiol/thioctic acid SAMs and the SPGEs was evaluated through CVs. Bare, $1 \mathrm{mM}$ carboxylate-dithiol and $100 \mathrm{mM}$ thioctic acid SAMmodified individual SPGEs (220AT) were immersed in thoroughly degassed PBS and two consecutive CVs were recorded from -0.50 to $-0.90 \mathrm{~V}$ at a scan rate of $10 \mathrm{mV} \mathrm{s}^{-1}$.

\subsection{TTX immobilization characterization}

The immobilization of TTX on carboxylate-dithiol SAM was performed following the protocol used for the development of the electrochemical immunosensor from steps 1 to 5 , but using individual SPGEs (220 AT) and $40 \mu \mathrm{L}$ of working volume instead of $15 \mu \mathrm{L}$. For the immobilization of TTX on thioctic acid, step 1 was performed using $40 \mu \mathrm{L}$ of $100 \mathrm{mM}$ thioctic acid in $\mathrm{MeOH}: \mathrm{H}_{2} \mathrm{O}(1: 1)$.

The immobilization of TTX on carboxylate-dithiol and thioctic acid SAMs was characterized by CV using 40 $\mu \mathrm{L}$ of $2.5 \mathrm{mM}$ potassium hexacyanoferrate redox couple (1:1, $5 \mathrm{mM}$ potassium hexacyanoferrate (II):5 mM potassium hexacyanoferrate (III)) in $0.1 \mathrm{M}$ phosphate buffer solution with $0.1 \mathrm{M} \mathrm{KCl}, \mathrm{pH} 7.2$. CVs were recorded from -0.25 to $+0.45 \mathrm{~V}$ at scan rate of $10 \mathrm{mV} \mathrm{s}^{-1}$ on bare SPGEs, $1 \mathrm{mM}$ carboxylate-dithiol and 100 $\mathrm{mM}$ thioctic acid SAM-modified electrodes, after ethylendiamine addition, and after TTX immobilization $(5,000 \mathrm{ng} / \mathrm{mL})$. All steps were carried out using the same electrode, rinsing thoroughly with wash buffer between steps.

\section{7. $M E L I S A$}

Briefly, the 5 puffer fish samples analyzed by the electrochemical immunosensor developed herein were also analyzed by the mELISA as previously reported [27]. All puffer fish tissue extracts were analyzed at a matrix concentration of $40 \mathrm{mg} \mathrm{mL}^{-1}$. Puffer fish extracts of $L$. sceleratus, containing high levels of TTX, were further diluted to allow for quantification within the working range $\left(\mathrm{IC}_{20}-\mathrm{I} \mathrm{C}_{80}\right)$. All samples, $\mathrm{mAb}$ and toxin standard solutions were prepared in PBS, diluted by half and assayed in triplicate. Quantifications were corrected by applying the mELISA correction factors (CFs) established for each tissue [27].

\subsection{SPR immunosensor}

The protocol used for the analysis of puffer fish samples was carried out as described in previous works [27, 36]. A TTX standard calibration curve was constructed from 0.06 to $1,000 \mathrm{ng} \mathrm{mL}^{-1}$. As for mELISA, all puffer fish extracts were analyzed at a matrix concentration of $40 \mathrm{mg} \mathrm{mL}^{-1}$. Puffer fish tissue extracts of $L$. 
sceleratus, containing high levels of TTX, were further diluted to allow for quantification within the working range $\left(\mathrm{IC}_{20}-\mathrm{IC}_{60}\right)$. All samples, $\mathrm{mAb}$ and toxin standard solutions were prepared in HBS-EP buffer, diluted by half and assayed in duplicate. As for mELISA quantifications, TTX contents obtained by the SPR immunosensor were corrected by applying the corresponding SPR CFs established for each tissue [27].

\subsection{LC-HRMS analysis}

The quantification of TTXs contents in five samples of puffer fish extracts of the species $L$. lagocephalus, $L$. sceleratus and S. pachygaster was performed following the protocol reported in Rambla-Alegre et al. [41]. The sum of total TTX as well as the individual TTX analogues concentrations were calculated for muscle, skin, liver and gonads tissues of five samples. To facilitate the comparison of the results with the other techniques used herein, only the sums of TTX contents are shown.

\subsection{Statistical analysis}

Correlations between TTX contents obtained by the electrochemical immunosensor and those obtained by mELISA, SPR immunosensor and LC-HRMS analysis were evaluated using linear regression. To evaluate if differences were significant between techniques, data were tested for normality using the Shapiro-Wilk test. For data following a normal distribution, t-test was performed; otherwise, Mann-Whitney Rank Sum Test was performed. The level of significance was set at $p<0.05$. All statistics were performed using Sigmastat 3.1 software (Systat Software Inc. California, US).

\section{Results and discussion}

Due to the similar affinity of maleimide and gold for thiol groups, the SAM-based strategy used for the development of the mELISA reported previously [27] was followed for the development of the present electrochemical immunosensor, whereby maleimide plates were replaced by SPGEs and the electrochemical signal was recorded instead of the colorimetric one. Prior to the development of the electrochemical immunosensor, the SAM formation as well as the different steps for the immobilization of TTX on SAMs were characterized.

\subsection{SAM characterization by reductive desorption}

Since thiolated compounds have been proven to experience desorption from gold surfaces at negative potentials under highly alkaline or neutral $\mathrm{pH}$ solutions, reductive desorption experiments were carried out to 
characterize the self-assembling of carboxylate-dithiol and thioctic acid on individual SPGEs (corresponding structures are shown in Figure 2). Figure 3 shows the forward scans of the two consecutive CVs carried out on bare SPGEs and carboxylate-dithiol SAM-modified SPGEs. As expected, no reduction peaks were observed when using bare SPGEs (dotted line) in any of the scans. On the contrary, a peak at $-0.8 \vee$ was obtained in the first scan on SAM-modified electrodes (solid line), which corresponds to the reduction of thiol groups $[42,43]$. In the second scan, no peak was obtained, suggesting that the negative potential applied to the electrodes caused the complete thiol bond break in the first scan, and demonstrating the previous presence of SAM on the modified electrode. Although being destructive, this technique has been useful to characterize the carboxylate-dithiol SAM formation. Unfortunately, thioctic acid SAM-modified SPGEs did not provide a suitable response (no reduction peak was observed), but the strategy was retained for further evaluation.

\subsection{Characterization of TTX immobilization on SAMs}

The different steps for the immobilization of TTX on carboxylate-dithiol and thioctic acid SAMs were monitored by $\mathrm{CV}$. The $\mathrm{CVs}$ of the $\left[\mathrm{Fe}(\mathrm{CN})_{6}\right]^{3-14-}$ at bare, SAM, ethylendiamine and TTX-immobilized SPGEs were recorded (Figure 4). Both SAMs resulted in a decrease of the electrochemical signal due to the lower permeability of the electrode, being drastic in the case of thioctic acid and only slight in the case of carboxylate-dithiol. As described in the work performed by Fragoso and co-workers [44], the length and structure of thiolated molecules as well as the corresponding orientation and SAM packaging could influence the charge transfer in the ferrocyanide solution. In this case, despite being longer, carboxylate-dithiol provides a monolayer with the long chains of polyethylene glycol and spaced slightly titled from the perpendicular to the electrode surface, which favors the electron transfer. On the contrary, the shorter thioctic acid-based SAM was more packed and the short alkyl chain obliquely oriented to the electrode, resulting in a higher electron transfer blocking. When the positively charged ethylendiamine was added to the thioctic acid SAM-based SPGEs, oxidation and reduction peaks did not substantially change, probably due to the high blocking effect from the thioctic acid. On the contrary, the ethylendiamine addition significantly counteracted the blocking effect caused by the carboxylate-dithiol, as it is demonstrated by the reappearance of the well-defined oxidation and reduction peaks. Finally, an appropriate CV response after TTX immobilization was obtained for carboxylate-dithiol SAM-modified SPGEs (only a mild improvement was observed when using thioctic acid). Indeed, this result together with the unsatisfactory results obtained in the SAM reductive experiment for thioctic acid SAM reinforce the hypothesis that carboxylate-dithiol SAMs was 
the only choice for the immunosensor development. The orientation provided by carboxylate-dithiol probably favors the TTX immobilization and, consequently, the subsequent antigen-antibody affinity interaction. Furthermore, the spacing effect of carboxylate-dithiol SAM may not only favor the antigen-antibody affinity interaction, but also eases the electrochemical redox mediator to reach the electrode surface, thus, promoting the electron transfer. Given the improved orientation and permeability displayed by the carboxylate-dithiol SAM strategy, thioctic acid was no longer used in the development of the electrochemical biosensor.

\subsection{Electrochemical immunosensor development}

In order to select the optimal concentrations of carboxylate-dithiol, TTX and mAb, electrochemical titrations were performed using conventional TMB as redox mediator. On the evaluation of the carboxylate-dithiol concentration although $0.1 \mathrm{mM}$ of carboxylate-dithiol provided a proper layer in the mELISA configuration, this concentration did not provide sufficient current intensities $(<1 \mu \mathrm{A})$ in the electrochemical approach, probably due to the different surface properties of the SPGEs. Therefore, the following experiments were performed using $1 \mathrm{mM}$ of carboxylate-dithiol, which provided higher current intensities $(>2 \mu \mathrm{A})$. Afterwards, immobilization of TTX on SAMs was assessed using the concentration of TTX required for the mELISA configuration of $0.5 \mu \mathrm{g} \mathrm{mL}^{-1}$ [27]. This TTX concentration was examined with different mAb dilutions: 1/800, $1 / 1,600$ and $1 / / 3,200$. Controls without $m A b$ were included in the checkerboard to have an indication of the non-specific binding of the HRP-labelled secondary antibody on the system. At this concentration, similar reduction current intensities were attained regardless of the antibody concentration (around $2 \mu \mathrm{A}$ ), suggesting that at $0.5 \mu \mathrm{g} \mathrm{mL}^{-1}$ of TTX, the SAM was completely saturated of mAb even when using the $1 / 3,200$ dilution. As the high non-specific adsorption values (between 60 and $70 \%$ ) seem to indicate, this amount of TTX would not be enough to fully cover the specific binding sites of the SAM and whereby these sites could be non-specifically occupied by the secondary antibody. In order to obtain higher current intensities, a higher TTX concentration $\left(2 \mu \mathrm{gL}^{-1}\right)$ was used in the immobilization step. In this case, higher current intensities were attained and a trend was observed according to the different mAb dilutions (4.2, 3.4 and $2.8 \mu \mathrm{A}$ for $1 / 800,1 / 1,600$ and 1/3,200 dilutions, respectively). As expected, the non-specific binding from the secondary antibody followed the opposite trend $(35,44$ and $52 \%$, respectively). Therefore, the use of a higher TTX concentration for the immobilization step increased the specific response and lowered the nonspecific binding. 
In order to evaluate the sensitivity of the immunosensor, electrochemical competition assays were carried out with $1 \mathrm{mM}$ of carboxylate-dithiol, $2 \mu \mathrm{g} \mathrm{mL}-1$ of TTX and several free TTX concentrations to choose between the three mAb dilutions. While the signal provided by the highest antibody dilution $(1 / 3,200)$ was not sufficient to discriminate between different TTX concentrations, significant differences in the current intensity were observed when using $1 / 800$ and 1/1,1600 mAb dilutions. As expected, slightly better sensitivity was achieved with $1 / 1,600$ than with $1 / 800 \mathrm{mAb}$ dilutions $(50 \%$ of $\mathrm{mAb}$ binding corresponding to 40 and $80 \mathrm{ng} \mathrm{mL}^{-1}$ of TTX, respectively). Therefore, conditions selected to perform further competitive assays were: $1 \mathrm{mM}$ of carboxylate-dithiol, $2 \mu \mathrm{g} \mathrm{mL}{ }^{-1}$ of TTX in the immobilization step and 1/1,600 mAb dilution. The shift from the colorimetric to the electrochemical approach required using 10-fold higher concentration of carboxylate-dithiol, 40-fold higher of TTX, and double mAb concentration, due to the different surface characteristics of maleimide-coated microtiter wells and SPGEs.

With the aim of improving the electron transfer, thus, increasing further the current intensities, a different redox mediator (enhanced TMB) was used at the same conditions. Compared to conventional TMB, enhanced TMB provided current intensities 4 -fold higher, as well as $5 \%$ less of non-specific binding. These differences are probably due to the different nature of the final product resulting from the enzyme reaction. While the product of the reaction with conventional TMB is in liquid form, an insoluble precipitate is produced when the enzyme reacts with enhanced TMB. This solid precipitate concentrates at the electrode surface, enhancing the electrochemical response. Given the higher intensities and lower non-specific binding values obtained with enhanced TMB, the following experiments were performed with this mediator.

A calibration curve in buffer was then constructed using enhanced TMB (Figure 5) and, from the adjustment, a regression factor $(R)$ of 0.992 was obtained. Standard deviation (SD) for 4 replicates $(n=4)$ was $\leq 15 \%$ for all concentrations. Overall, the use of this mediator allows the improvement in sensitivity of the immunosensor, by lowering the $\mathrm{IC}_{50}$ from 40 to $7 \mathrm{ng} \mathrm{mL}^{-1}$. The LOD was found to be $2.6 \mathrm{ng} \mathrm{mL}^{-1}$, and the working range $\left(\mathrm{IC}_{20}-\mathrm{IC}_{60}\right)$ was $2.6-10.2 \mathrm{ng} \mathrm{mL}^{-1}$.

The sensitivity achieved by the present electrochemical immunosensor was in good agreement with the two electrochemical immunosensors reported for TTX [31,32]. In comparison with the previous works, this electrochemical immunosensor enables for the first time the detection of TTX by immobilizing the toxin on specific locations of a SAM through stable chemical bonds. This SAM-based approach provides an oriented, specific and spaced TTX sensing platform, avoiding the need to conjugate the toxin to protein carriers (e.g. BSA), which may block the electron transfer, and decreasing the non-specific binding thanks to the carboxylate-dithiol chemical structure. In addition, the new electrochemical platform has been characterized 
in detail, demonstrating the toxin immobilization as well as the enhanced electron transfer favored by the carboxylate-dithiol SAM. The shift from the colorimetric to the electrochemical SAM-based approach represents an advance towards disposable, portable and compact devices for the detection of TTX. In addition to these benefits, the multiplexed configuration permits reducing the reagent volumes (only $15 \mu \mathrm{L}$ per electrode) as well as the consecutive measurement of 8 samples, decreasing the cost and analysis time.

\subsection{Evaluation of puffer fish matrix effects}

The applicability of the biosensor was first studied by evaluating matrix effects of blank puffer fish tissue extracts at a matrix concentration of $40 \mathrm{mg} \mathrm{mL}^{-1}$ (from a sample determined as non-containing TTX by LCMS/MS). The analysis of negative puffer fish extracts at $40 \mathrm{mg} \mathrm{mL}^{-1}$ of tissue resulted in mAb binding percentages of $91,106,95$ and $103 \%$ for muscle, skin, liver, and gonads, respectively. Taking into account that the highest SD in the calibration curve was of $15 \%$, a response between 85 and $115 \%$ of mAb binding indicates no effect from the extract. Thus, matrix effects can be considered negligible at $40 \mathrm{mg} \mathrm{mL}^{-1}$ of puffer fish matrix.

Further matrix effects were then evaluated through the spiking of 2.5, 5 and $10 \mathrm{ng} \mathrm{mL}^{-1}$ of TTX into blank puffer fish tissue extracts at a matrix concentration of $40 \mathrm{mg} \mathrm{mL}^{-1}$ (corresponding to $0.06,0.13$ and $0.25 \mathrm{mg}$ TTX kg-1 of tissue, respectively). Percentages of toxin were calculated with reference to the concentrations of TTX spiked (Table 1). Again, taking into account the $15 \%$ of SD, similar TTX concentrations were determined in buffer and in spiked puffer fish tissue extracts, reaffirming that matrix does not interfere with the immunosensor performance.

Given the negligible matrix effects and the good toxin percentages observed in spiked-extracts, the analysis of puffer fish tissue extracts can be performed using $40 \mathrm{mg} \mathrm{mL}^{-1}$ of matrix, which means that the immunosensor should be able to detect as low as $0.07 \mathrm{mg}$ TTX equiv. $\mathrm{kg}^{-1}$ tissue. These results proven the reliability and feasibility of this biosensor to be applied to the analysis of samples with complex matrices such as puffer fish extracts.

\subsection{Analysis of naturally contaminated puffer fish samples and comparison with mELISA, SPR immunosensor and LC-HRMS analysis}

In order to demonstrate the applicability of the electrochemical immunosensor, L. lagocephalus, L. sceleratus and S. pachygaster samples were analyzed. Quantifications obtained by this immunosensor were compared with those determined by mELISA, SPR immunosensor and LC-HRMS. Whereas no TTX was found in either 
L. lagocephalus or S. pachygaster puffer fish samples (mAb binding percentages between 85 and 115\%), high TTX contents were determined in L. sceleratus tissues by all techniques. Table 2 shows the TTX equivalent contents determined in L. sceleratus extracts by the electrochemical immunosensor, mELISA and SPR immunosensor, in addition to the sum of the total TTX content obtained by LC-HRMS (the individual content of TTX and each analogue provided by LC-HRMS [41].

Among the species of puffer fish analyzed in this work, L. sceleratus is considered one of the most toxic Lessepsian invasive species of the Mediterranean [45]. L. lagocephalus is a native species of the Mediterranean for which there are no known specific toxin threats and, consequently, has been listed as least concern by a European Regional Assessment [46]. Finally, S. pachygaster is a well-known alien species of the Mediterranean [47], considered weakly toxic by Noguchi et al. [48], but non-toxic in the Mediterranean by Ragonese and co-workers [49]. Therefore, the toxin contents found in this work for different puffer fish species were in accordance with the levels of TTX described in the literature for these species of puffer fish caught along the Mediterranean coast.

With regard to the distribution of TTX in L. sceleratus tissues, the same trend was obtained with all the techniques used in this study, whereby the highest to the lowest TTX content was found in: gonads>liver>skin>muscle. Distribution of TTX into tissues was in accordance with that described for other female $L$. sceleratus specimens captured along the Mediterranean [17, 27, 50, 51]. Notably, levels of TTX found in gonads and liver tissues were up to 10 -fold above the Japanese value of $2 \mathrm{mg}$ TTX eq. $\mathrm{kg}^{-1}$ used as criterion to judge the acceptability of puffer fish as safe for human consumption [10].

When comparing the techniques used for the analysis of $L$. sceleratus extracts, a good correlation is obtained between the TTX contents determined by the electrochemical immunosensor and those provided by mELISA ( $\left.R^{2}=0.933\right)$, as well as equivalent quantifications $(y=0.95 x-1.81 ; t=0.245, P=0.815)$. The similarity between results obtained with both techniques is due to the fact that both approaches are based on the antigen-antibody affinity principle and, additionally, TTX immobilization was achieved using the same strategy. Even though the transducer and the detection method are different, the recognition of antibody antigen binding and the competition step are similar.

When comparing the TTX contents determined by the electrochemical method with those provided by the SPR immunosensor, results correlate well $\left(R^{2}=0.907\right)$, and equivalent TTX contents are reported by SPR immunosensor $(y=1.05 x-3.05 ; \mathrm{t}=0.221, \mathrm{P}=0.833)$. Despite the different approach used in the TTX immobilization (oriented through dithiols self-assembled on gold electrodes vs. randomly on dextran chips), the different detection principles of these techniques (electrochemical vs. optical) and the measurement of 
the biorecognition event (end-point vs. real-time), comparable toxin contents were obtained, with no significant differences.

Finally, in order to compare the quantifications obtained by this immunosensor with those provided by LCHRMS, the known cross-reactivity factors (CRFs) [27] were applied to the individual contents of TTX and analogues. As the similar recognition event occurs between immunosensor and immunoassay, and due to the lack of available TTX analogues, CRFs established by mELISA [27] were assumed for this immunosensor. Good correlation was obtained between both techniques $\left(R^{2}=0.902\right)$ and, as observed in the previous study [27], slightly lower contents were determined by LC-HRMS, although differences were statistically not significant $(y=1.28 x+2.78 ; \mathrm{t}=0.538, \mathrm{P}=0.610)$. As mentioned in the previous work [41], within the different tissues analyzed, the greatest disparity between the quantifications provided by mELISA and LC-HRMS was observed in case of the liver. The lack of CRFs for some analogues determined by LCHRMS, the possible presence of unknown analogues as well as other matrix components could be responsible for this disagreement between techniques.

Overall, TTX contents determined by the electrochemical immunosensor were in good agreement with those obtained by mELISA, SPR immunosensor and LC-HRMS. Table 3 reviews and compares the main analytical parameters of each technique. The good agreements found between the quantifications provided by this immunosensor and those provided by the other techniques proved the reliability and usefulness of the biosensor in the analysis of puffer fish samples. Certainly, this biosensor enabled the screening of TTX in several puffer fish species and tissues, from which S. pachygaster and L. lagocephalus individuals were considered safe for human consumption, whereas L. sceleratus was determined risky for human safety because of the high TTX contents determined, according to the Japanese criterion.

\section{Conclusions}

Encouraged by the necessity to develop alternative methods to MBA and LC-MS/MS analysis for the detection of the emerging TTX in European fish and shellfish, an immunosensing platform based on the TTX immobilization through dithiols self-assembled on 8-gold electrode arrays is described. The spaced and oriented TTX immobilization on the carboxylate-dithiol SAM as well as the choice of a precipitating redox mediator favored the electron transfer. Good sensitivity was attained by the immunosensor, with an LOD of $2.6 \mathrm{ng} \mathrm{mL}^{-1}$.

The immunosensor allowed working with the high loading tissue concentration of $40 \mathrm{mg} \mathrm{mL}^{-1}$ and showed no matrix effects under these conditions. Therefore, taking into account the LOD in buffer and the tolerable 
matrix concentration, the immunosensor was able to detect as low as $0.07 \mathrm{mg}$ equiv. TTX $\mathrm{kg}^{-1}$ tissue. TTX contents determined in puffer fish samples by the electrochemical immunosensor were in good agreement with those obtained by mELISA, SPR immunosensor and LC-HRMS analysis. Thus, the analytical performance of the SAM-based electrochemical immunosensor shows feasibility for its implementation in food safety programs, since it enables the determination of TTX in puffer fish well below the Japanese value of $2 \mathrm{mg}$ equiv. TTX kg-1 tissue and provides TTX quantifications comparable to other techniques. The format of the immunosensor described in this work makes it promising as a screening tool, with advantages such as the possible integration in miniaturized devices, the use of low reagent volumes, and the short time required for the consecutive analysis of 8 samples. In conclusion, given the improved sensitivity, the high accuracy and the good agreement of the immunosensor with other methods, this work constitutes a breakthrough in the development of rapid, compact, robust, reliable and easy-to-use analysis devices for the detection of the emerging TTX in puffer fish samples.

The authors declare that there is no conflict of interests regarding the publication of this paper.

\section{Figure legends}

Figure 1. Schematic representation of the electrochemical immunosensor array platform for TTX detection.

Figure 2. Carboxylate-dithiol and thioctic acid molecules self-assembled on SPGEs.

Figure 3. Forward scan voltammograms obtained in degassed PBS for bare SPGE (dashed line), scan 1 (solid line) and scan 2 (dotted line) of carboxylate-dithiol SAM-modified SPGE at a scan rate of $10 \mathrm{mV} \mathrm{s}^{-1}$.

Figure 4. Cyclic voltammograms in $2.5 \mathrm{mM}\left[\mathrm{Fe}(\mathrm{CN})_{6}\right]^{3-14-}$ at $10 \mathrm{mV} \mathrm{s}^{-1}$ obtained at (a) bare, (b) SAM, (c) ethylendiamine and (d) TTX-immobilised SPGEs for carboxylate-dithiol and thioctic acid approaches.

Figure 5. Calibration curve obtained by the electrochemical immunosensor. mAb binding is expressed as percentage of the control (without free toxin). $\mathrm{X}$ values refer to initial toxin concentrations and error bars show standard deviation (SD) for 4 replicates $(n=4)$.

\section{References}

[1] E.G. Moczydlowski. The molecular mystique of tetrodotoxin, Toxicon, 63 (2013) 165-183.

[2] V. Pratheepa, V. Vasconcelos. Microbial diversity associated with tetrodotoxin production in marine organisms, Environmental Toxicology and Pharmacology, 36 (2013) 1046-1054.

[3] Y. Tahara, Y. Hirata. Studies on the puffer fish toxin, J. Pharm. Soc. Jpn, 29 (1909) 587-625.

[4] T. Noguchi, O. Arakawa. Tetrodotoxin - Distribution and accumulation in aquatic organisms, and cases of human intoxication, Marine Drugs, 6 (2008) 220-242.

[5] K. Tsuda, R. Tachikawa, C. Tamura, S. Ikuma, M. Kawamura, K. Sakai, O. Amakasu. On structure of tetrodotoxin, Chem. Pharm. Bull., 12 (1964) 642-+. 
[6] R.B. Woodward, J.Z. Gougouta. Structure of tetrodotoxin J. Am. Chem. Soc., 86 (1964) 5030-\&.

[7] C.H. Lee, P.C. Ruben. Interaction between voltage-gated sodium channels and the neurotoxin, tetrodotoxin, Channels, 2 (2008) 407-412.

[8] T. Noguchi, K. Onuki, O. Arakawa. Tetrodotoxin poisoning due to pufferfish and gastropods, and their intoxication mechanism, ISRN toxicology, 2011 (2011) 276939-276939.

[9] J. You, Y. Yue, F. Xing, W. Xia, S. Lai, F. Zhang. Tetrodotoxin poisoning caused by Goby fish consumption in southeast China: a retrospective case series analysis, Clinics, 70 (2015) 24-29.

[10] Y. Mahmud, K. Yamamori, T. Noguchi. Occurrence of TTX in a brackish water puffer "Midorifugu", Tetraodon nigroviridis, collected from Thailand, Shokuhin Eiseigaku Zasshi, 40 (1999) 363-367.

[11] European Comission. Regulation (EC) No. 853/2004 of the European Parliament and of the Council of 29 April 2004 laying down specific hygiene rules for food of animal origin Off. J. Eur. Union 2004, L139, 22-82.

[12] European Comission. Regulation (EC) No 854/2004 of the European Parliament and of the Council of 29 April 2004 laying down specific rules for the organisation of official controls on products of animal origin intended for human consumption Off. J. Eur. Union 2004, L226, 83-127.

[13] T. Peck, Want to eat the world's most deadly dish? Join the club (2011). Available online: http://www.independent.co.uk/life-style/food-and-drink/news/want-to-eat-the-worlds-most-deadly-dish-jointhe-club-2292393.html. Accessed by December 2016.

[14] N.J. Cohen, J.R. Deeds, E.S. Wong, R.H. Hanner, H.F. Yancy, K.D. White, T.M. Thompson, M. Wahl, T.D. Pham, F.M. Guichard, I. Huh, C. Austin, G. Dizikes, S.I. Gerber. Public health response to puffer fish (tetrodotoxin) poisoning from mislabeled product, Journal of Food Protection, 72 (2009) 810-817.

[15] Y. Bentur, J. Ashkar, Y. Lurie, Y. Levy, Z.S. Azzam, M. Litmanovich, M. Golik, B. Gurevych, D. Golani, A. Eisenman. Lessepsian migration and tetrodotoxin poisoning due to Lagocephalus sceleratus in the eastern Mediterranean, Toxicon, 52 (2008) 964-968.

[16] P. Rodriguez, A. Alfonso, C. Vale, C. Alfonso, P. Vale, A. Tellez, L.M. Botana. First toxicity report of tetrodotoxin and 5,6,11-trideoxyTTX in the trumpet shell Charonia lampas lampas in Europe, Anal. Chem., 80 (2008) 5622-5629.

[17] P. Katikou, D. Georgantelis, N. Sinouris, A. Petsi, T. Fotaras. First report on toxicity assessment of the Lessepsian migrant pufferfish Lagocephalus sceleratus (Gmelin, 1789) from European waters (Aegean Sea, Greece), Toxicon, 54 (2009) 50-55.

[18] J. Kheifets, B. Rozhavsky, Z. Girsh Solomonovich, R. Marianna, A. Soroksky. Severe tetrodotoxin poisoning after consumption of Lagocephalus sceleratus (pufferfish, fugu) fished in Mediterranean Sea, treated with cholinesterase Inhibitor, Case rep. Crit. Care (2012) 782507-782507.

[19] A.D. Turner, A. Powell, A. Schofield, D.N. Lees, C. Baker-Austin. Detection of the pufferfish toxin tetrodotoxin in European bivalves, England, 2013 to 2014, Euro surveill., 20 (2015) 2-8.

[20] A. Vlamis, P. Katikou, I. Rodriguez, V. Rey, A. Alfonso, A. Papazachariou, T. Zacharaki, A.M. Botana, L.M. Botana. First Detection of tetrodotoxin in Greek shellfish by UPLC-MS/MS potentially linked to the presence of the dinoflagellate Prorocentrum minimum, Toxins, 7 (2015) 1779-1807.

[21] RASFF Consumers Portal. Notification details - 2016.0845. Possible presence of tetrodotoxin in live oysters from the Netherlands. https://webgate.ec.europa.eu/rasffwindow/consumers/?event=notificationDetail\&NOTIF REFERENCE $=2016.0845 \&$ country $=$ NL. Accessed by December 2016.

[22] M. Asakawa, Shida, Y., Miyazawa, K., Noguchi, T., InTech Open Science, Rijeka, Croatia, 2012, p.

245.

[23] T. Kawabata, Tetrodotoxin. In: Veterinary Division, environmental health bureau, ministry of health and welfare (Ed.), Food hygiene examination manual (Shokuhin Eisei Kensa Shishin) II. Japan Food Hygiene Association, Tokyo, pp. 223-241 1978b.

[24] T.J.G. Raybould, G.S. Bignami, L.K. Inouye, S.B. Simpson, J.B. Byrnes, P.G. Grothaus, D.C. Vann. A monoclonal antibody-based immunoassay for detecting tetrodotoxin in biological samples, J. Clin. Lab. Anal., 6 (1992) 65-72.

[25] K. Kawatsu, Y. Hamano, T. Yoda, Y. Terano, T. Shibata. Rapid and highly sensitive enzyme immunoassay for quantitative determination of tetrodotoxin, Jpn. J. Med. Sci. Biol., 50 (1997) 133-150.

[26] J. Tao, W.J. Wei, L. Nan, L.H. Lei, H.C. Hui, G.X. Fen, L.Y. Jun, Z. Jing, J. Rong. Development of competitive indirect ELISA for the detection of tetrodotoxin and a survey of the distribution of tetrodotoxin in the tissues of wild puffer fish in the waters of south-east China, Food Addit. Contam. Part A, 27 (2010) 1589-1597.

[27] L. Reverté, P. de la Iglesia, V. del Río, K. Campbell, C.T. Elliott, K. Kawatsu, P. Katikou, J. Diogène, M. Campàs. Detection of tetrodotoxins in puffer fish by a self-assembled monolayer-based immunoassay and comparison with surface plasmon resonance, LC-MS/MS, and mouse bioassay (vol 87, pg 10839, 2015), Anal. Chem., 88 (2015) 2511-2511.

[28] Y. Zhou, Y.S. Li, F.G. Pan, Z.S. Liu, Z. Wang. Identification of tetrodotoxin antigens and a monoclonal antibody, Food Chem., 112 (2009) 582-586. 
[29] A.N. Stokes, B.L. Williams, S.S. French. An improved competitive inhibition enzymatic immunoassay method for tetrodotoxin quantification, Biol. Proced. Online, 14 (2012) 5.

[30] Q. Zhong, A. Huang, B. Wang, X. Dong, in: Z. Cao, Y.H. He, L. Sun, X.Q. Cao (Eds.), Application of Chemical Engineering, Pts 1-3, 2011, p. 2820-2824.

[31] M.P. Kreuzer, M. Pravda, C.K. O'Sullivan, G.G. Guilbault. Novel electrochemical immunosensors for seafood toxin analysis, Toxicon, 40 (2002) 1267-1274.

[32] D. Neagu, L. Micheli, G. Palleschi. Study of a toxin-alkaline phosphatase conjugate for the development of an immunosensor for tetrodotoxin determination, Anal. Bioanal. Chem., 385 (2006) 10681074.

[33] A.D. Taylor, J. Ladd, S. Etheridge, J. Deeds, S. Hall, S.Y. Jiang. Quantitative detection of tetrodotoxin (TTX) by a surface plasmon resonance (SPR) sensor, Sens. Actuator B-Chem., 130 (2008) 120128.

[34] A.D. Taylor, H. Vaisocherova, J. Deeds, S. DeGrasse, S. Jiang. Tetrodotoxin detection by a surface plasmon resonance sensor in pufferfish matrices and urine, J. Sens. (2011) 601704.

[35] H. Vaisocherova, A.D. Taylor, S. Jiang, K. Hegnerova, M. Vala, J. Homola, B.J. Yakes, J. Deeds, S. DeGrasse. Surface plasmon resonance biosensor for determination of tetrodotoxin: Prevalidation study, J. of AOAC Int., 94 (2011) 596-604.

[36] K. Campbell, P. Barnes, S.A. Haughey, C. Higgins, K. Kawatsu, V. Vasconcelos, C.T. Elliott. Development and single laboratory validation of an optical biosensor assay for tetrodotoxin detection as a tool to combat emerging risks in European seafood, Anal. Bioanal. Chem., 405 (2013) 7753-7763.

[37] M. Campàs, D. Garibo, B. Prieto-Simón. Novel nanobiotechnological concepts in electrochemical biosensors for the analysis of toxins, Analyst, 137 (2012) 1055-1067.

[38] S. Leonardo, L. Reverté, J. Diogène, M. Campàs. Biosensors for the detection of emerging marine toxins. D. P. Nikolelis, G.-P. Nikoleli (Eds.), In: Biosensors for security and bioterrorism applications, Springer. Switzerland, (2016), 231-248.

[39] M. Campàs, B. Prieto-Simon, J.-L. Marty. Biosensors to detect marine toxins: Assessing seafood safety, Talanta, 72 (2007) 884-895.

[40] L. Reverté, B. Prieto-Simón, M. Campàs. New advances in electrochemical biosensors for the detection of toxins: Nanomaterials, magnetic beads and microfluidics systems. A review, Analytica Chimica Acta, 908 (2016) 8-21.

[41] M. Rambla-Alegre, L. Reverté, V. del Río, P. de la Iglesia, O. Palacios, C. Flores, J. Caixach, K. Campbell, C.T. Elliott, A. Izquierdo-Muñoz, M. Campàs, J. Diogène, Evaluation of tetrodotoxins in puffer fish caught along the Mediterranean coast of Spain. Toxin profile of Lagocephalus sceleratus, Environ. Res., in press.

[42] K. Sun, B. Jiang, X.Y. Jiang. Electrochemical desorption of self-assembled monolayers and its applications in surface chemistry and cell biology, J. Electroanal. Chem., 656 (2011) 223-230.

[43] M. Tencer, P. Berini. Toposelective Electrochemical Desorption of Thiol SAMs from Neighboring Polycrystalline Gold Surfaces, Langmuir, 24 (2008) 12097-12101.

[44] A. Fragoso, N. Laboria, D. Latta, C.K. O'Sullivan. Electron permeable self-assembled monolayers of dithiolated aromatic scaffolds on gold for biosensor applications, Anal. Chem., 80 (2008) 2556-2563.

[45] N. Streftaris, A. Zenetos. Alien Marine Species in the Mediterranean - the 100 'Worst Invasives' and their Impact, Mediterr. Mar. Sci., 7 (2006) 87-117.

[46] C. Papakonstantinou, A.D. Rijnsdorp, Lagocephalus lagocephalus. The IUCN Red List of Threatened Species 2015: e.T190464A45883323. http://www.iucnredlist.org/details/summary/190464/1. Accessed by december 2016, 2015.

[47] D. Golani, L. Orsi Relini, E. Massuti, J.P. Quignard, 2010. CIESM atlas of exotic species in the Mediterranean. Vol. 1 Fishes. CIESM publisher, Monaco. World Wide Web electronic publication, accessible at: http://www.ciesm.org/online/atlas/index.htm

[48] T. Noguchi, O. Arakawa. Tetrodotoxin - Distribution and accumulation in aquatic organisms, and cases of human intoxication, Mar. Drugs, 6 (2008) 220-242.

[49] S. Ragonese, U. Morara. Evidence of short-term discard mortality of trawled Sphoeroides pachygaster (Osteichthyes, Tetraodontidae) off the southern coast of Sicily (Central Mediterranean Sea), Panam. J. Aquat. Sci., 7 (2012) 73-76.

[50] P. Rodriguez, A. Alfonso, P. Otero, P. Katikou, D. Georgantelis, L.M. Botana. Liquid chromatography-mass spectrometry method to detect tetrodotoxin and its analogues in the puffer fish Lagocephalus sceleratus (Gmelin, 1789) from European waters, Food Chem., 132 (2012) 1103-1111.

[51] A.R. Kosker, F. Ozogul, M. Durmus, Y. Ucar, D. Ayas, J.M. Regenstein, Y. Ozogul. Tetrodotoxin levels in pufferfish (Lagocephalus sceleratus) caught in the Northeastern Mediterranean Sea, Food Chem., 210 (2016) 332-337.

\section{Acknowledgements}


The research leading to these results has received funding from the European Union Seventh Framework Programme (FP7/2007-2013) under the ECsafeSEAFOOD project (grant agreement $n^{\circ} 311820$ ) and the Instituto Nacional de Investigación y Tecnología Agraria y Alimentaria (INIA) through the PROMAQUA project (RTA2013-00096-00-00). L.R. acknowledges a scholarship from the ECsafeSEAFOOD project. 
Table 1. Toxin percentages measured by the electrochemical immunosensor array platforms in spikedmuscle, skin, liver and gonads tissue extracts of $L$. lagocephalus with reference to the TTX spiked levels (0.06, 0.13 and $0.25 \mathrm{mg}$ TTX kg-1 of tissue).

\begin{tabular}{|c|c|c|c|}
\hline \multirow[b]{2}{*}{ Puffer fish tissue } & \multicolumn{3}{|c|}{ TTX spiked level (mg TTX $\mathrm{kg}^{-1}$ tissue) } \\
\hline & 0.06 & 0.13 & 0.25 \\
\hline Muscle & $104 \%$ & $112 \%$ & $113 \%$ \\
\hline Skin & $89 \%$ & $87 \%$ & $97 \%$ \\
\hline Liver & $93 \%$ & $89 \%$ & $106 \%$ \\
\hline Gonads & $96 \%$ & $114 \%$ & $87 \%$ \\
\hline
\end{tabular}

Table 2. TTX equivalent contents (mg TTX equiv. $\mathrm{kg}^{-1}$ tissue) in $L$. sceleratus extracts obtained by the electrochemical immunosensor, mELISA and SPR immunosensor, and the sum of total TTX determined by LC-HRMS analysis. LODs were $0.23,0.43$ and $0.05 \mathrm{mg} \mathrm{kg}^{-1}$ for mELISA, SPR immunosensor and LCHRMS, respectively.

\begin{tabular}{ccccc}
\hline Puffer fish tissue & Electrochemical immunosensor & mELISA [41] & SPR immunosensor & $\boldsymbol{\Sigma}$ LC-HRMS [41] \\
\hline Muscle & 1.45 & 2.53 & 3.51 & 0.98 \\
Skin & 2.11 & 3.50 & 4.42 & 2.08 \\
Liver & 16.67 & 25.30 & 24.82 & 5.36 \\
Gonads & 33.90 & 33.55 & 30.50 & 25.22 \\
\hline
\end{tabular}


Table 3. Comparison of the performance parameters: LOD, high throughput sample analysis, ease of sample preparation, ease of use, cost and portability provided by the different analytical techniques used in this work.

\begin{tabular}{|c|c|c|c|c|c|c|}
\hline Technique & $\begin{array}{c}\text { LOD } \\
\text { (mg TTX } \\
\mathbf{k g}^{-1} \\
\text { puffer } \\
\text { fish) }\end{array}$ & $\begin{array}{c}\text { High- } \\
\text { throughput } \\
\text { sample } \\
\text { analysis }\end{array}$ & $\begin{array}{c}\text { Ease of } \\
\text { sample } \\
\text { preparation* }\end{array}$ & $\begin{array}{c}\text { Ease of } \\
\text { use }\end{array}$ & Cost & Portability \\
\hline $\begin{array}{l}\text { Electrochemical } \\
\text { immunosensor }\end{array}$ & 0.07 & medium & yes & medium & medium & high \\
\hline mELISA & 0.23 & high & no & high & medium & medium \\
\hline $\begin{array}{c}\text { SPR } \\
\text { immunosensor }\end{array}$ & 0.43 & high & no & medium & high & low \\
\hline LC-HRMS & 0.05 & high & no & low & high & low \\
\hline
\end{tabular}

${ }^{*}$ According to the requirement of solvent evaporation for solvent exchange. 
FIGURE 1

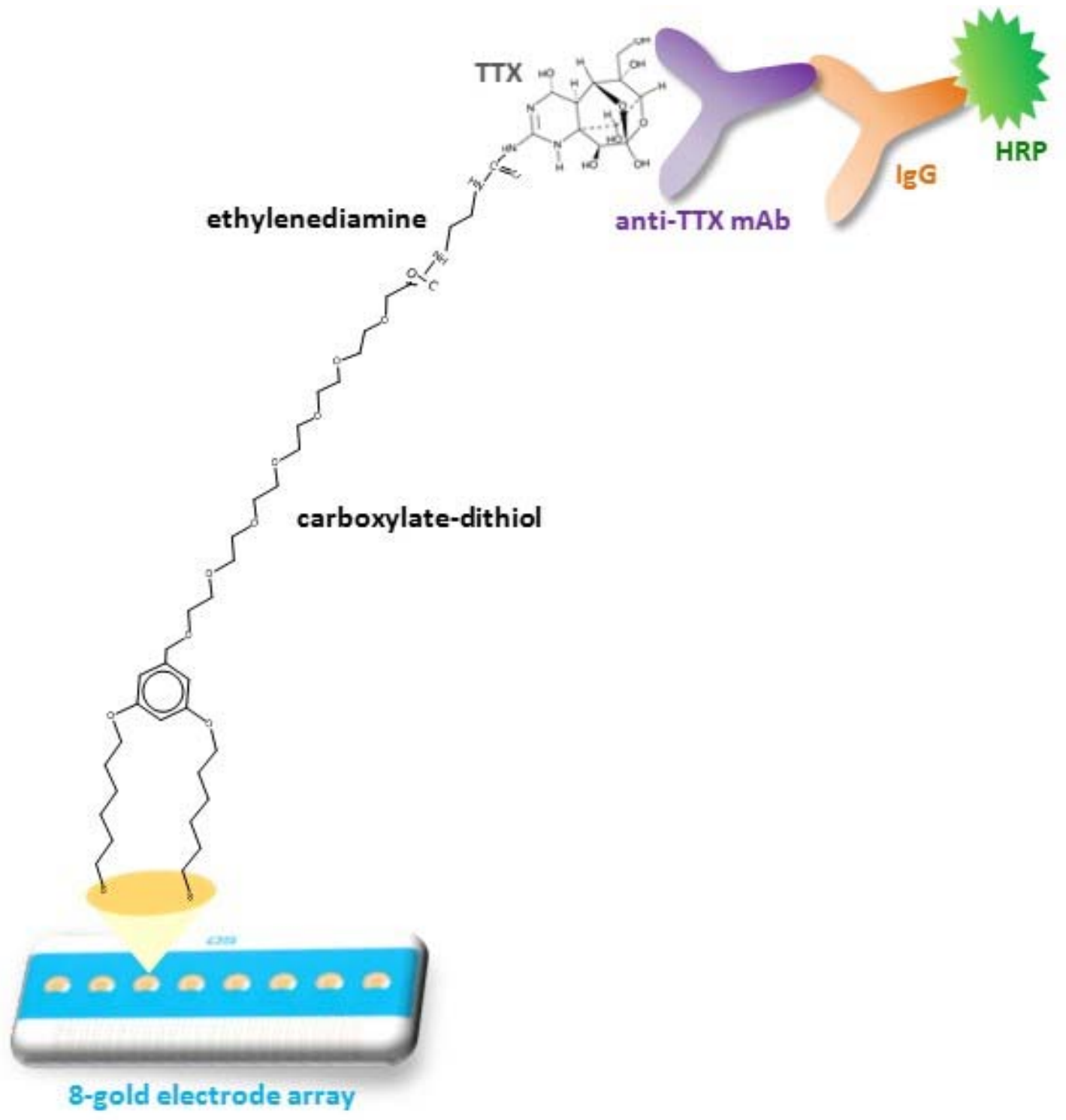


FIGURE 2

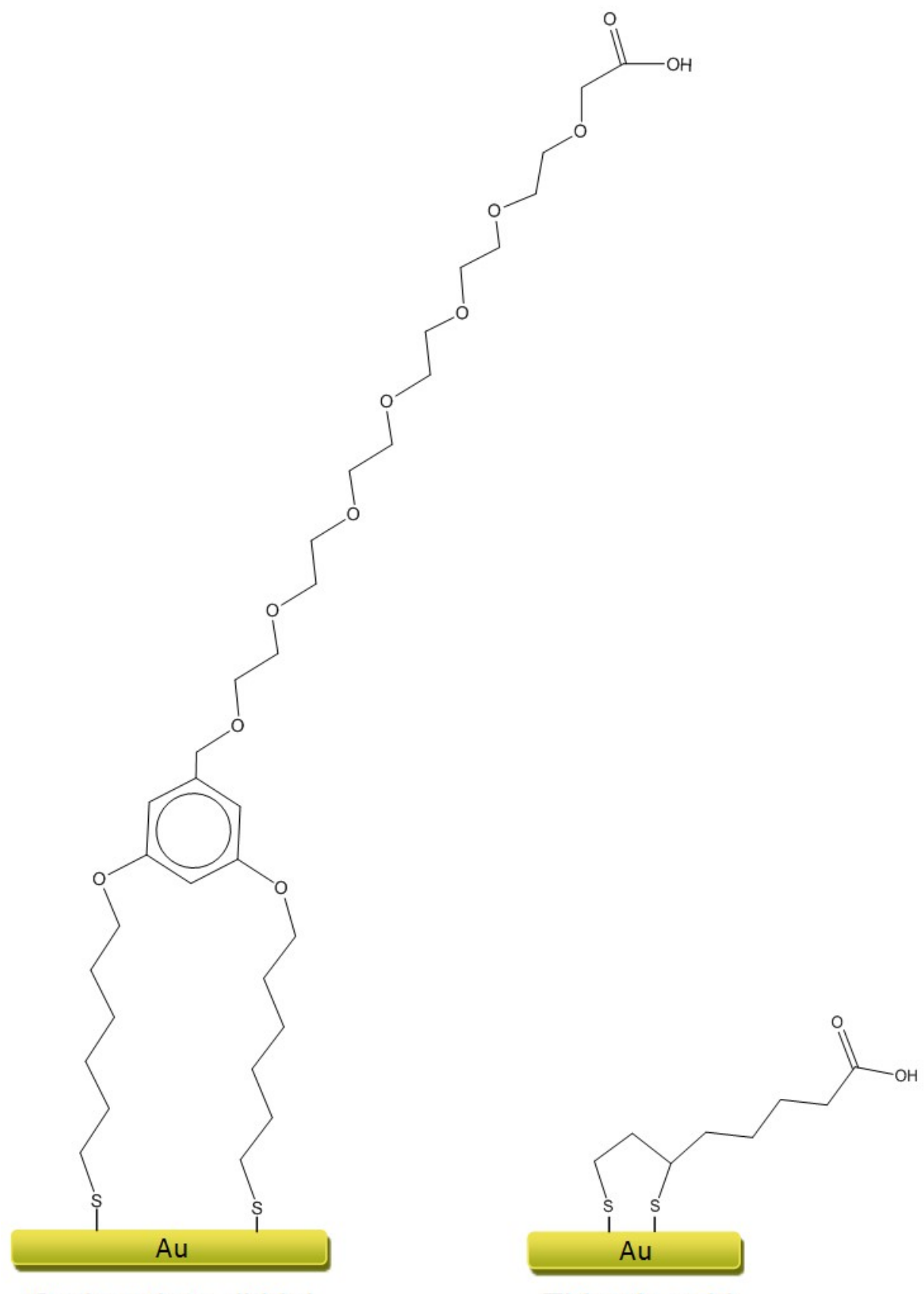

Carboxylate-dithiol

Thioctic acid 
FIGURE 3

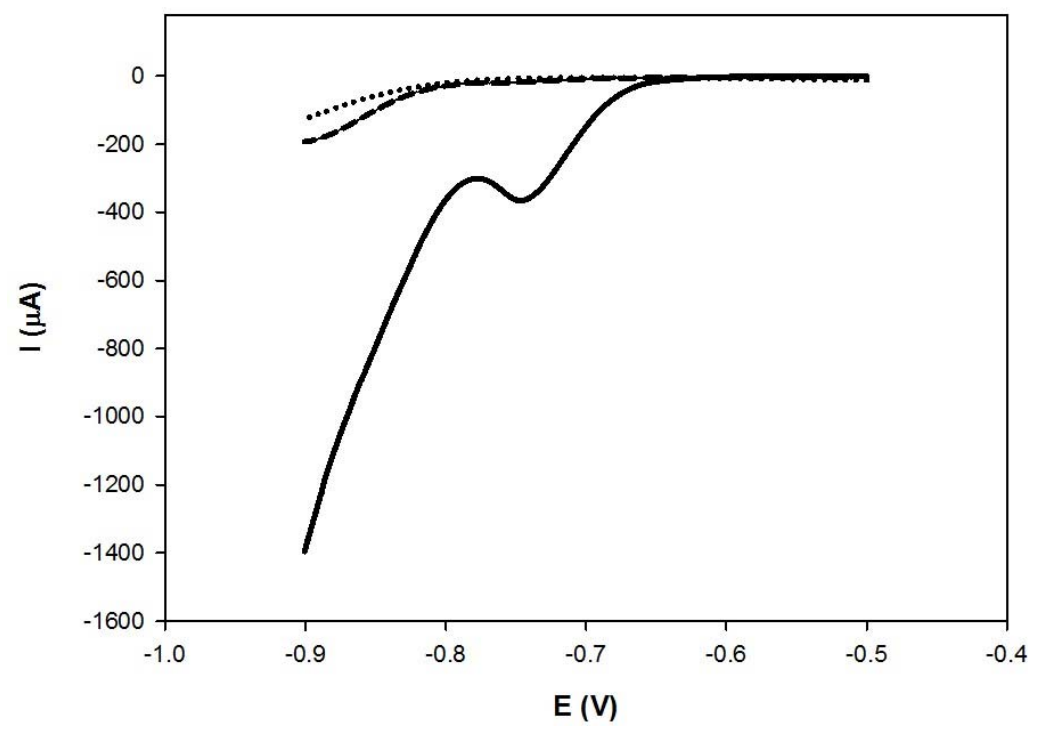

FIGURE 4

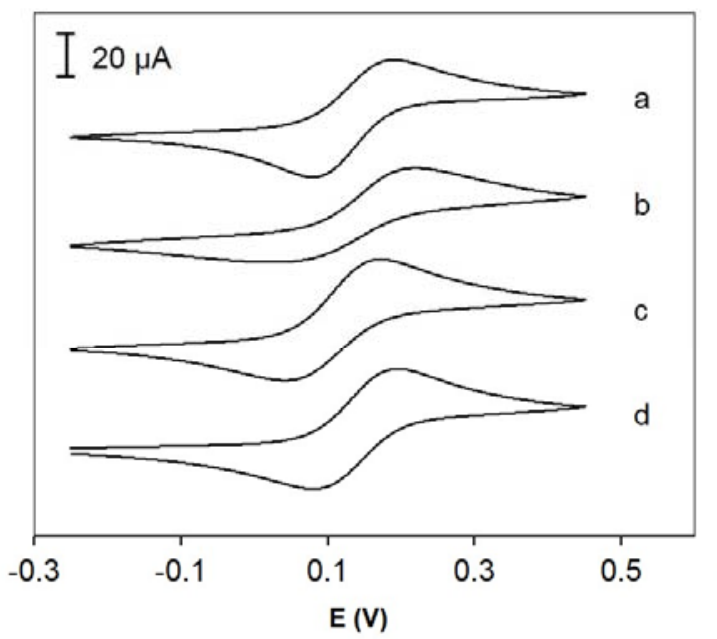

Carboxylate-dithiol

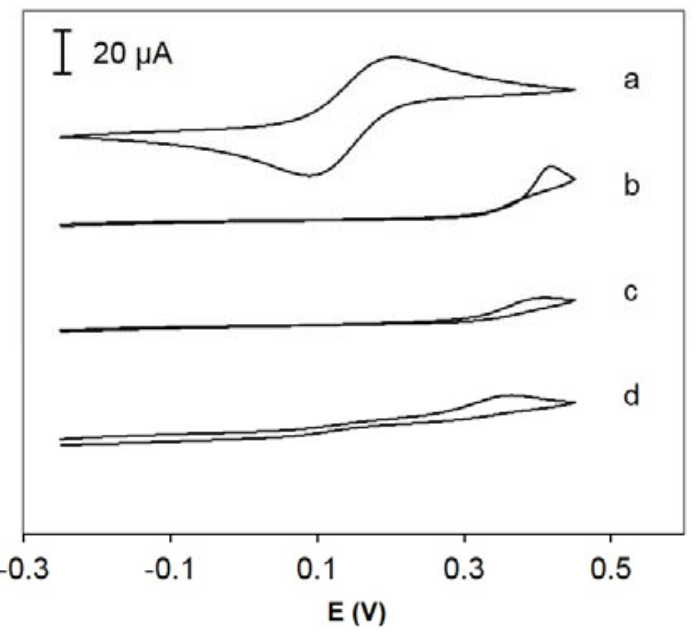

Thioctic acid 
FIGURE 5

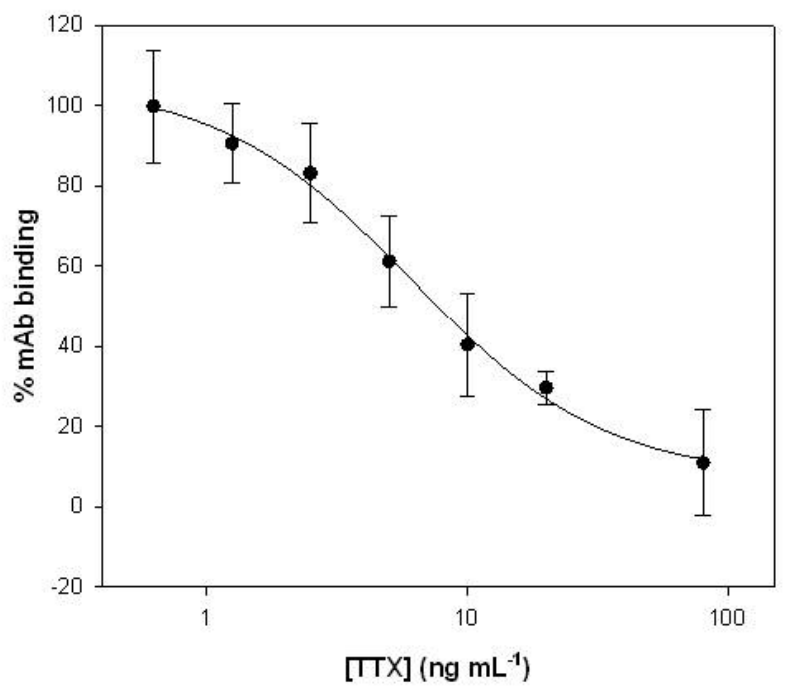

